\title{
Evaluation of management, control, complications and psychosocial aspects of diabetics in Bangladesh: DiabCare Bangladesh 2008
}

\author{
Latif $\mathrm{ZA}^{1}$, Jain $\mathrm{A}^{2}$, Rahman $\mathrm{MM}^{3}$

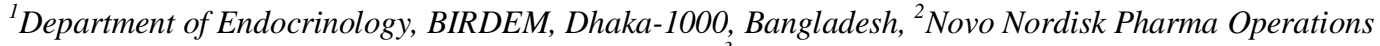 \\ (BAOS) Sdn Bhd, Kuala Lumpur, Malaysia 59000, ${ }^{3}$ Novo Nordisk Pharma (Pvt.) Ltd, Bangladesh.
}

\begin{abstract}
DiabCare Bangladesh 2008 evaluated the current status of diabetes care in Bangladesh as a continuation of similar cross-sectional study conducted previously in 1998. The current study recruited 1952 patients from general hospitals, diabetes clinics and referral clinics to study current scenario of diabetes management from 01 March 2009 to 31 March 2009. We report the results of type 2 diabetic population who constituted $95.3 \%(\mathrm{n}=1860)$. Results showed deteriorating glycaemic control with mean $\mathrm{HbA} 1 \mathrm{c}$ of $8.6 \pm 2.0 \%$ with only $23.1 \%$ of the patients achieving American Diabetes Association (ADA) target of $<7 \% .896(47.0 \%)$ patients were hypertensive and $850(94.9 \%)$ were on antihypertensive medication. $70.8 \%$ of patients had LDL levels $>2.6 \mathrm{mmol} / \mathrm{L} ; 43.8 \%$ had triglycerides $>2.2 \mathrm{mmol} / \mathrm{L} ; 44.1 \%$ had $\mathrm{HDL}<1 \mathrm{mmol} / \mathrm{L}$ despite $48 \%$ of the patients being on lipid lowering agents. Microvascular, macrovascular and severe late complications were reported in $39.2 \%, 9.9 \%$ and $12.1 \%$ patients respectively. The rates of diabetic complications were cataract $12.9 \%$, microalbuminuria $15.7 \%$, neuropathy symptoms $31.7 \%$, leg amputation $1.2 \%$ and history of angina pectoris was $6.6 \%$. Quality of life evaluation showed that about half of patients have poor quality of life. Also, there was poor adherence to diet, exercise and self testing of blood glucose. In conclusion, majority of the patients were still not satisfactorily controlled. There is an urgent need for effective remedial measures to increase adherence to practice guidelines and to educate both patients and healthcare personnel on importance of achieving clinical targets for metabolic control.
\end{abstract}

\section{Introduction}

Population studies all over the world have clearly showed that the prevalence of diabetes mellitus (DM) is escalating and very likely we are heading towards epidemic proportions. Worldwide prevalence of diabetes in adults was estimated to be $4.0 \%$ in 1995 and expected to rise to $5.4 \%$ by the year 2025. The number of adults with diabetes in the world is expected to rise from 135 million in 1995 to 300 million in the year 2025. The major part of this numerical increase will occur in developing countries. There will be a $42 \%$ increase, from 51 to 72 million, in the developed countries and a $170 \%$ increase, from 84 to 228 million, in the developing countries. Thus, by the year 2025, $75 \%$ of people with diabetes will reside in developing countries, as compared with $62 \%$ in $1995^{1}$.

The incidence of diabetes in the Asian population is on the rise; hence the incidence of late diabetes complications is also expected to increase correspondingly. Amongst the countries in Asia, India has got the highest number of people suffering from diabetes. When it comes to impaired glucose tolerance, Indonesia and Singapore figure in the top ten countries in the world ${ }^{2}$.
This exponential increase in the number of people with diabetes puts an enormous burden on both healthcare authorities and healthcare providers. Prevention and control programmes are needed to stem the rising epidemic of diabetes and its complications. However, these will not occur unless governments and public health planners are aware of the potential problem.

Surveillance of diabetes is a necessary first step toward its prevention and control, which is now recognized as an urgent priority. Furthermore, a reliable baseline status is fundamental to any improvement program. To fulfill this purpose, a multinational project - DiabCare Asia - was initiated in 1997 with the collaboration of Novo Nordisk in 6 countries and soon expanded to 11 in $1998^{3,4}$. Projects like DiabCare monitor diabetes care status through participation of large number of patients and clinicians. It appraises the performance of health promotion and the healthcare system over time which helps in guiding public health policies. DiabCare Bangladesh 2008 was planned as a crosssectional, observational study to evaluate the current prevailing scenario of diabetes mellitus management, control, complications, quality of life 
and psychosocial aspects of patients in order to correlate with the findings of previous studies.

\section{Material \& Methods}

This was non-interventional, cross-sectional, observational study. This study included both type 1 and type 2 patients. Data was collected from 100 centers across Bangladesh. The primary objective was to evaluate diabetes management, control and complication profile in patients with diabetes. Secondary objectives included studying psychosocial aspects of diabetic patients and to evaluate perceptions and practices of physicians about diabetes management. Patients with diabetes registered in the particular center for more than a year with at least one visit in the 3-6 months preceding the study were included. Eligible patients were explained the study purpose and invited to attend another clinic visit. Informed consent was obtained from these patients. Data was collected during the study visit by review of medical records, clinical examination, laboratory assessments and personal interview. Patient data included demography, medical history, risk factors, selfmonitoring data, diabetes education, complications, eye and foot examinations and diabetes management. HbA1c was measured for all the patients recruited in this study.

Data collected during the study visit was systematically captured in standardized case report forms (CRFs) designed for this study. Novo Nordisk was responsible for collecting completed CRFs from participating centres and for data management.

The patient questionnaire was adapted from the DAWN survey to evaluate quality of life. This questionnaire consisted of three parts: a) WHO-5 Well Being Index, b) Psychosocial questionnaire, c) Compliance questionnaire ${ }^{5,6}$. At each centre, the investigator completed a questionnaire designed to capture the physicians' perceptions about various aspects of diabetes management.

The results of patients with only type 2 diabetes are presented in this report.

\section{HbAlc Measurement}

The method used for estimation was BioRad HPLC D10. The blood samples from all the study subjects during the study visit were collected in Sodiumheparinised capillaries, hemolysed in aqueous solution and stored between $-20^{\circ} \mathrm{C}$ to $-80^{\circ} \mathrm{C}$ in the respective centres until collected by the centralized laboratory. All blood samples were transported to the central laboratory within 24 hours for testing.
The blood samples after $\mathrm{HbA} 1 \mathrm{C}$ analysis were promptly disposed.

Statistical Methods:

Sample size was calculated based upon the prevalence of various microvascular and macrovascular complications in the country, as they give a broad picture of diabetic control and care prevalent in Bangladesh. For calculation of sample size, country-specific rates (based upon IDF Diabetes Atlas 3rd Edition) of neuropathy, nephropathy, retinopathy and cardiovascular complications were considered. The complication which is least prevalent (CVD) amongst type 1 and type 2 diabetes was chosen for sample-size calculation in order to provide adequate probability of capturing even the lowest occurring complication in the country. Windows-based software (PEPI, version 4) by PM Gahlinger and JH Abhramson, 1993-2001, was used for samplesize calculation with $5 \%$ level of significance, $90 \%$ power and 20-30\% margin of error.

The data set for analysis was confined to the following range of values for various parameters viz. age (18-85 years), BMI $\left(18-40 \mathrm{Kg} / \mathrm{m}^{2}\right), \mathrm{HbAlc}$ (4-16\%), FPG 54-306 mg/dl (3-17 mmol/), PPG $54-500 \mathrm{mg} / \mathrm{dl}(3-27.77 \mathrm{mmol} / \mathrm{l})$ and the duration of diabetes up to 25 years. Statistical methods were similar to those of the earlier published DiabCare studies. Descriptive statistics were used to summarize continuous variables; primary endpoints presented as mean \pm standard deviation (SD), range or percentage and secondary endpoints as number and percentage. Logistic regression was used to analyse the relationship between complications (cataract, serum creatinine $>2 \mathrm{mg} / \mathrm{dl}$, symptoms of neuropathy and macrovascular complications - all expressed as a binary outcome, present or absent) and risk factors [predicted by age, sex (male or female), age at onset, duration of diabetes, hypertension (present or absent), insulin therapy (yes or no), HbA1c, FPG and SMBG (testing done or not done)]. Adjusted odds ratios for all complications were computed for two of the predictor variables viz., age at onset and duration of diabetes. All tests were two-sided and a p value of less than 0.05 was considered to be significant.

\section{Results}

Demography of Study Population:

A total of 1952 patients were included in the study. Of the total population, type 2 diabetes patients numbered 1860 (95.3\%). Demographic and metabolic characteristics of type 2 population are elaborated in Table I. 
Table I: Demographic and metabolic characteristics

\begin{tabular}{|c|c|}
\hline $\begin{array}{l}\text { Demographic and metabolic } \\
\text { characteristics }\end{array}$ & Data \\
\hline Age (years)* & $50.9 \pm 11.4$ \\
\hline \multicolumn{2}{|l|}{ Age groups: } \\
\hline$<65 / \geq 65$ years & $1054 / 130(89 / 11 \%)$ \\
\hline Gender, male/female & $956 / 987(48.1 / 51.9 \%)$ \\
\hline $\operatorname{BMI}\left(\mathrm{kg} / \mathrm{m}^{2}\right)^{*}$ & $24.9 \pm 3.5$ \\
\hline \multicolumn{2}{|l|}{ BMI groups: } \\
\hline$\geq 23 / \geq 25 \mathrm{~kg} / \mathrm{m}^{2}$ & $78.2 / 50.3 \%$ \\
\hline Duration of diabetes (years)* & $7.9 \pm 10.4$ \\
\hline \multicolumn{2}{|l|}{ Waist circumference: $(\%)$} \\
\hline Male $(\geq 90 \mathrm{~cm}) /$ Female $(\geq 80 \mathrm{~cm})$ & $46.6 / 73.4 \%$ \\
\hline \multicolumn{2}{|l|}{ Duration of diabetes groups: $(\%)$} \\
\hline$\leq 1 / 1-5 />5-10 />10$ years & $8.9 / 40.2 / 30.4 / 20.5 \%$ \\
\hline Age at onset (years)* & $42.1 \pm 14.2$ \\
\hline \multicolumn{2}{|l|}{ Income groups: } \\
\hline Low/ Middle/ High & $\begin{array}{l}637 / 1068 / 185(33.7 / \\
56.5 / 9.8 \%)\end{array}$ \\
\hline \multicolumn{2}{|l|}{ Educational status } \\
\hline LCTRW $^{\#}$ & $348(18 \%)$ \\
\hline 5 years & $549(28.3 \%)$ \\
\hline 10 years & $607(31.3 \%)$ \\
\hline Graduate & $333(17.2 \%)$ \\
\hline Postgraduate & $101(5.2 \%)$ \\
\hline \multicolumn{2}{|l|}{ Risk factors } \\
\hline Family history & $977(52.8 \%)$ \\
\hline Smoking & $156(8.2 \%)$ \\
\hline Alcohol & $4(0.2 \%)$ \\
\hline \multicolumn{2}{|l|}{ Health expenses } \\
\hline Self & $1834(96.5 \%)$ \\
\hline Government/ Community & $66(3.5 \%)$ \\
\hline Insurance & $1(0.1 \%)$ \\
\hline
\end{tabular}

*Data expressed as mean \pm SD. BMI, body mass index; OAD, oral antidiabetic drug; SU, Sulphonylurea; BG, Biguanide; AGD, Alpha glucosidase inhibitors; TZD, Thiazolidinediones; \#Limited Capacity To Read and Write

Main cohort, type 2 diabetes mellitus, $n=1860$, Percentage calculated out of available data

\section{Glycaemic control:}

The mean $\mathrm{HbAlc}$ level of patients as assessed by the patient records and survey during the course of this study was $8.24 \pm 2.4 \%$ and $8.6 \pm 2.0 \%$ respectively. The frequency of testing for FPG and HbA1c was $4 \pm 4.7$ and $3.7 \pm 5.3$ times respectively over the preceding one year. The mean fasting and postprandial glucose levels of patients measured were $8.4 \pm 2.7 \mathrm{mmol} / \mathrm{l}$ and $8.5 \pm 2.8 \mathrm{mmol} / \mathrm{l}$, respectively. When fasting and postprandial plasma glucose levels were stratified according to ADA guidelines, it showed that only $40.3 \%$ and $69.3 \%$ of patients had glycaemic control within the recommended levels (Table II). The mean HbA1c values increased significantly $(p<0.0001)$ with duration of diabetes. In the similar way the mean FPG and PPG values also increased significantly $(p<0.0001)$ with the duration of diabetes.

\section{Cardiovascular risk factors:}

The mean LDL-cholesterol, HDL-cholesterol and triglyceride levels of patients were $3.21 \pm 1.09$, $1.09 \pm 0.76$ and $2.24 \pm 1.10 \mathrm{mmol} / \mathrm{l}$, respectively. $70.8 \%$ of patients had LDL levels $>2.6 \mathrm{mmol} / \mathrm{L}$; $43.8 \%$ had triglycerides $>2.2 \mathrm{mmol} / \mathrm{L} ; 44.1 \%$ had $\mathrm{HDL}<1 \mathrm{mmol} / \mathrm{L}$ (Lipid targets as defined by American Heart Association and ADA). Of the 1163 patients with dyslipidemia, $47.9 \%$ were treated with lipid lowering drugs. Statins were the most commonly (36.9\%) prescribed lipid lowering agents.

Table II: HbA1c Levels (Survey) Stratified by Various Types of Guidelines ( $\mathrm{N}=1784)$

\begin{tabular}{llccc}
\hline Guideline & \multicolumn{1}{c}{ Definition } & Range (\%) & $\mathrm{N}$ & $\begin{array}{c}\text { Proportion of } \\
\text { Patients }(\%)\end{array}$ \\
\hline ADA & Recommended & $<7.0$ & 412 & 23.1 \\
& Not within the & $=>7.0$ & 1372 & 76.9 \\
& recommended level & & & \\
EUDPG & Low Risk & $\leq 6.5$ & 260 & 14.6 \\
(Type 2) & Arterial Risk & $>6.5-7.5$ & 355 & 19.9 \\
& Microvascular Risk & $>7.5$ & 1169 & 65.6 \\
APDPG & Optimal & $<6.5$ & 234 & 13.1 \\
(Type 2) & Fair & $6.5-7.5$ & 381 & 21.4 \\
& Poor & $>7.5$ & 1169 & 65.5 \\
\hline
\end{tabular}

The mean blood pressure of the study population was $126.7 \pm 14.9$ / $80.4 \pm 7 \mathrm{mmHg}$. Hypertension was observed in $896(47 \%)$ of patients. Of the 896 patients with hypertension, 850 (94.9\%) were taking anti-hypertension medicine. Beta blockers and $\mathrm{Ca}^{+2}$ antagonist were used by majority of patients $(34.7 \%)$ followed by ACE inhibitors (34\%) and angiotensin II receptor blockers (30.9\%). When categorized according to duration of diabetes, the DBP changed significantly $(\mathrm{p}<0.05)$ with duration of diabetes.

Diabetic complications

Diabetic complications are given in Table III.

Table III: Proportion of Patients with Different Complications of Diabetes

\begin{tabular}{lcc}
\hline \multicolumn{1}{c}{ Complications of Diabetes } & $\mathrm{N}$ & $\begin{array}{c}\text { Proportion of } \\
\text { patients }(\%)\end{array}$ \\
\hline Cataract $(\mathrm{n}=1087)$ & 140 & 12.9 \\
Non-proliferative diabetic retinopathy $(\mathrm{n}=1080)$ & 77 & 7.1 \\
Proliferative diabetic retinopathy $(\mathrm{n}=1059)$ & 15 & 1.4 \\
Microalbuminuria $(\mathrm{n}=212)$ & 34 & 15.7 \\
Serum creatinine >2 mg/dL $(\mathrm{n}=997)$ & 30 & 3.3 \\
Neuropathy Symptoms $(\mathrm{N}=1158)$ & 367 & 31.7 \\
Absent Ankle Jerk $(\mathrm{n}=822)$ & 337 & 41.1 \\
Leg amputation (n=842) & 10 & 1.2 \\
Absent foot pulses (n=825) & 48 & 5.8 \\
Angina pectoris (n=1731) & 115 & 6.6 \\
Myocardial infarction (n=1579) & 82 & 5.2 \\
Cerebral stroke (n=1704) & 37 & 2.2 \\
Severe late complications ( $\mathrm{n}=1860)$ & 225 & 12.1 \\
Micro-vascular complications $(\mathrm{n}=1860)$ & 729 & 39.2 \\
Macro-vascular complications $(\mathrm{n}=1860)$ & 185 & 9.9 \\
\hline
\end{tabular}

Severe late complications: Patients with any or all of the following complications -Legal blindness, MI, CABG/Angioplasty/ Stents, Cerebral stroke, ESRD and Leg amputation

Microvascular complications: Patients with any or all of following complications-Retinopathy, nephropathy and neuropathy. Macrovascular complications: Patients with any or all of following complications -Angina pectoris, MI, CABG/Angioplasty/ Stents, Stroke. 
Diabetes Management

Diabetes management is given in Table IV.

Table IV: Diabetes management (DiabCare Bangladesh 2008)

\begin{tabular}{|c|c|}
\hline OADs & $\mathrm{N}=1860$ \\
\hline No OADs & $202(10.9)$ \\
\hline Biguanides & $1009(54.2)$ \\
\hline Sulphonylureas & $1038(55.8)$ \\
\hline Meglinitides & $41(2.2)$ \\
\hline Glucosidase & $27(1.5)$ \\
\hline Thiazolidenedione & $239(12.8)$ \\
\hline GLP-1 Analogues & $1(0.05)$ \\
\hline DPP-4 Inhibitors & $1(0.05)$ \\
\hline Traditional/Herbal & $1(0.05)$ \\
\hline Double Drug & $43(2.3)$ \\
\hline Triple Drug & $4(0.2)$ \\
\hline \multicolumn{2}{|c|}{ Insulin therapy } \\
\hline Patients on insulin $(n=1799)$ & $769(42.7 \%)$ \\
\hline $\begin{array}{l}\text { Human insulin / Analogue insulin } \\
(\mathrm{n}=1799)\end{array}$ & $757 / 21(42.1 / 1.2 \%)$ \\
\hline Duration of insulin therapy (years) & $4.1 \pm 6.9$ \\
\hline Dosage of insulin therapy (U/day) & $35.5 \pm 41.7$ \\
\hline Pens/ syringes $(\%)(\mathrm{n}=777)$ & $105 / 672(13.5 / 81.5 \%)$ \\
\hline $\begin{array}{l}\text { Number of injections per day } \\
1 / 2 />2\end{array}$ & $26 / 687 / 68(3.3 / 88.0 / 8.7 \%)$ \\
\hline
\end{tabular}

Few patients $(8.3 \%)$ were treated with anti-obesity treatment. About $10.1 \%$ were treated with antiplatelet treatment and about $21.5 \%$ were treated with aspirin. The proportion of patients practising home blood glucose monitoring was low at $21.5 \%$. Majority of patients have received general diabetes education $(62.7 \%)$, education on diet $(61.02 \%)$ and education on foot care (48.3\%).

\section{Patient perceptions}

a. Psychological Well-being:

Responses to questions on psychological wellbeing fell largely in the positive territory with most patients indicating that either all or most of the time, they felt "cheerful and in good spirits" $(90.4 \%)$, "calm and relaxed" (88.6\%) and "active and vigorous" (85\%), that they "woke up feeling fresh and vigorous" (87.5\%) and that their daily lives had been filled with things that interested them $(82.4 \%)$.

\section{b. Quality of Life}

When patients were queried about their quality of life, the majority "fully agreed" or "mainly agreed" to the statement that they felt that their "diabetes is well regulated". At the same time, the majority "fully disagree" or "mainly disagreed" with the questions "I am constantly afraid of my disease getting worse", "I am tired of complying with my medications" "I feel that my diabetes is preventing me from doing what I want to do" "I am worried about the risk of hypoglycaemic events" "coping with diabetes is more difficult at present than it used to be", and "I feel burned-out from having to cope with diabetes".

\section{c. Adherence to Treatment}

When patients were queried about their adherence to treatment, about half of the patients replied that they "completely" adhered to dietary (53.9\%) and exercise $(50 \%)$ recommendations. The majority of patients also said that they "completely" took medications as prescribed (70\%) and kept appointments with health care professionals (53\%), but with regards to following self-test recommendations from doctors and nurses, 36.4\% replied that they never did so.

\section{Physicians' Perceptions}

Majority of physicians preferred to estimate HbA1c. More than half of the participated physicians preferred to do HbAlc test 4 times a year. Almost all the physicians advocated the selfmonitoring of blood sugar by patients, and believed that insulin analogues offer distinct advantages over human insulin. All physicians recommended the modern insulin delivery devices and believed that patient education helps to achieve treatment goals. All physicians opined that wrong perceptions on insulin use, cost of insulin, fear of injection and other perceptions like insulin usage indicates the end stage of diabetes or insulin means lifelong treatment are the barriers for insulin therapy.

\section{Discussion}

DiabCare Bangladesh 2008, a cross-sectional survey provided an overview of the diabetes care rendered in the last one year. It provides a better understanding of the trends in quality of care and the implementation of learning from the previous study. Data were collected from a cohort of diabetic patients at 100 centres across Bangladesh, who had been registered in that centre for the management of diabetes for more than 12 months. A total of 1952 patients were participated in this study.

The current study cohort has 1860 (97.1\%) with type 2 diabetes. In DiabCare Bangladesh 1998 study, 1503 type 2 diabetic patients were recruited. ${ }^{7}$ For type 2 diabetic patients in present study, the age was $50.9 \pm 11.4$, duration of diabetes $7.9 \pm 10.4$, age of diabetes onset $-42.1 \pm 14.2$ and duration of treatment was $6.6 \pm 5.4$ years. In DiabCare Bangladesh 1998, the age of the patient was $50.95 \pm 10.32$ years, duration of diabetes was $6.78 \pm$ 5.38 years. In the present study, there was a slight preponderance of males to females $(1.08: 1)$ whereas in DiabCare Bangladesh 1998, the male:female ratio was $1.5: 1$. The BMI observed in this study was $24.9 \pm 3.5 \mathrm{~kg} / \mathrm{m}^{2}$ similar to that of 1998 study $\left(24.29 \pm 3.27 \mathrm{~kg} / \mathrm{m}^{2}\right)$, however, the 
proportion of patients with $\geq 25 \mathrm{~kg} / \mathrm{m}^{2}$ were higher in this study as compared to that of 1998 study (50.3\% vs. $37.7 \%$ in 2008 and 1998 studies respectively).

Glycemic control appears to be poorer among patients in the present study, with patients having high centrally-measured mean HbAlc as compared

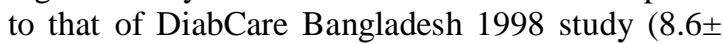
$2.0 \%$ vs. $7.9 \pm 1.85 \%$ ). Corresponding to these values, when HbA1c values were categorised according to the ADA guidelines, there was a higher proportion of patients in the present study cohort having poor glycaemic control (HbA1c $\geq 7.0 \%$ : $76.9 \%$ in this study vs. $63.3 \%$ in 1998 study). The FPG level of patients was $8.4 \pm 2.7$ $\mathrm{mmol} / \mathrm{L}$ in the present study which was lower than that of 1998 study $(9.07 \pm 3.3 \mathrm{mmol} / \mathrm{L})$. Nonetheless, PPG levels appeared to be comparable with FPG $(8.5 \pm 2.8 \mathrm{mmol} / \mathrm{l})$.

As lipid measurements were not centrally controlled in the study, this poses a limitation in attempting to draw a conclusion as to which patients had superior lipid control. Nonetheless, from the data that is available, mean HDL cholesterol was $1.09 \pm 0.76 \mathrm{mmol} / \mathrm{l}$, triglyceride level was $2.24 \pm 1.1 \mathrm{mmol} / \mathrm{l}$ (TG level was $2.30 \pm 1.3$ $\mathrm{mmol} / \mathrm{l}$ in 1998 study). TG levels more than the ADA recommended levels (>1.7 mmol/l) were higher in this study as compared to that of 1998 study (68\% vs. $63.4 \%$ respectively). In the present study, higher proportion of patients had co-morbid hypertension as compared to 1998 study $-47 \%$ vs. $35.8 \%$.

Data on diabetes-related complications was collected in the present study and the frequencies of complications were - cataract (12.9\%), advanced diabetic eye disease $(2.1 \%)$, leg amputation (1.2\%), absent foot pulse $(5.8 \%)$, active ulcer/gangrene (2.9\%), microalbuminuria (15.7\%), serum creatinine $>2 \mathrm{mg} / \mathrm{dl}(3.3 \%)$, neuropathy symptoms $(31.7 \%)$, cerebral stroke $(2.2 \%)$, myocardial infarction $(5.2 \%)$ while legal blindness appeared more prevalent $(7.1 \%)$. In 1998 study, the prevalence of diabetic complications were-cataract $13 \%$, advanced diabetic eye disease $0.7 \%$, retinopathy $(10.8 \%)$, photocoagulation $(0.3 \%)$, microalbuminuria $(17.5 \%)$, serum creatinine $>1.5$ $\mathrm{mg} \%-10.5 \%$, neuropathy $14.4 \%$. While prevalence of most of the diabetic complications remained similar from 1998 to 2008, there was high prevalence of neuropathy symptoms, advanced diabetic eye disease ${ }^{8}$.

Proportion of patients using OADs increased to $89.1 \%$ in the present study from $65.9 \%$ in DiabCare Bangladesh 1998 study. Sulphonylureas and biguanides were the most prescribed OADs $(55.8 \%$ and 54.2 respectively). The proportion of patients prescribed with insulin increased two-fold in the present study as compared to DiabCare Bangladesh 1998 study (42.7\% vs. $21.8 \%$ ). Human insulin was used by $98.4 \%$ of insulin users while $82.8 \%$ of insulin users used premix insulin. Majority of insulin users $(86.5 \%)$ used syringe. The proportion of insulin users and insulin dose increased with duration of diabetes although it was not statistically significant.

Responses to questions on psychological wellbeing fell largely in the positive territory. The majority of patients in the present cohort rated their quality of life of to be good or at least acceptable. $39 \%$ of patients in this present cohort who were not using insulin agreed with the statement that they were "very worried about having to start on insulin". Additionally, $39.1 \%$ of patients in this present cohort who were not using insulin agreed with the statement that "starting on insulin would mean that [they] have not followed [their] treatment recommendations properly". This may reflect the existence of 'psychological insulin resistance' among the present cohort - the reluctance to initiate insulin therapy in a timely manner, despite the demonstrated efficacy of insulin therapy in achieving and maintaining glycemic control in people with diabetes.

In this present study, physicians were asked to provide response to questions on physicians' perception questionnaire. This study highlights the challenges physicians face between managing diabetes while coping with the realities. The data indicate that there is a gap between the frequencies of HbA1c test recommended by the physicians versus real life practice. This gap may be filled by creating awareness on disease progression and related complications. Majority of physicians agreed with the goals of good glycemic control and preventing complications. Moreover, almost all physicians believed that analogues improve glycaemic control and advocated self monitoring of blood glucose and use of modern insulin devices like insulin pens.

Overall, the fact that majority of patients in the present study cohort had poor glycaemic control (HbA1c $>7.0 \%)$ suggests that there is scope for improvement. The importance of tight glycaemic control in preventing chronic complications has been previously underscored by a number of studies $^{9-15}$. Against the background of these studies, there seems to be a need for a large proportion of patients in the present study cohort to be upgraded to more intensive pharmacotherapy, with the ultimate goal of preventing the development of late onset complications. 
Conclusion:

Patients' poor glycemic control is a concern. Majority of patients (more than 50\%) had HbAlc and FPG levels above the recommended levels of many guidelines (ADA, EUDPG, APDPG, etc). To reduce the risk of diabetes-associated complications, glycaemia need to be maintained at a satisfactory level. There is a need for a large proportion of patients to be upgraded to more intensive insulin therapy and use of insulin analogues and modern delivery devices can help in achieving these goals effectively. The responses to patient reported outcome tools (WHO-5, DAWN QoL and Treatment adherence) call for more efforts to improve lifestyle modification, self-testing and awareness and benefits of insulin therapy. As with earlier DiabCare study, the present study also uncovers gaps in routine diabetes care and will help plan future interventions and monitor outcomes.

\section{Acknowledgements}

The authors would like to thank Novo Nordisk Bangladesh and South East Asia Oceania for generously providing grant for this study; Bangladesh Diabetic Somity (BADAS) and BIRDEM Hospital for granting permission to use their hospitals for this study and to all the investigators and staff of the various hospitals for their support.

\section{References}

1. King H, Aubert RE, Herman WH. Global Burden of Diabetes, 1995-2025 Prevalence, Numerical Estimates, and Projections. Diabetes Care 1998;21:1414-1431.

2. Sutanegara D, Darmono, Budhiaartha AAG. The epidemiology, and management of diabetes mellitus in Indonesia. Diabetes Research and Clinical Practice 2000;50: S9-S16.

3. Diabetes Care Data Collection Project Asia Pacific preliminary report. 9th Congress of AFES; Singapore; 1997.

4. Nitiyanant $\mathrm{W}$, Tandhanand S, Mahtab H, Zhu XX, Pan CY, Raheja BS, Sathe SR, Soegondo S, Soewondo P, Kim YS, Embong M, Lantion-Ang L, Lim-Abraham MA, Lee WW, Wijesuriya M, Tai TY, Chuang LM, Le HL, Cockram C, Jorgensen LN, Yeo JP. The DiabcareAsia 1998 study - outcomes on control and complications in type 1 and type 2 diabetic patients. Curr Med Res Opin 2002; 18(5): 317-327.

5. Bech P, Moses R, Gomis R. The effect of prandial glucose regulation with repaglinide on treatment satisfaction, wellbeing and health status in patients with pharmacotherapy-naïve Type 2 diabetes: a placebo-controlled, multicentre study. Qual Life Res 2003; 12: 413-425.

6. Shea S, Skovlund S, Bech P, Kalo I, Home P. Routine assessment of psychological well-being in people with diabetes - validation of the WHO-5 Well-Being Index in six countries. Diabetologia 2003; 46 (Suppl 2):A88.

7. Mahtab H, Kibriya M.G. The Diabcare-Asia, Bangladesh Project: Management of Diabetes in Bangladesh. Diabetes Research Clinical Practice 2000; 50 (Suppl.), P278: S55.

8. Kibriya M.G., Mahtab H. Micro-vascular complications in type 2 diabetes in Bangladesh: The Diabcare-Asia, Bangladesh Project. Diabetes Research Clinical Practice 2000; 50 (Suppl.), P553: S135.

9. Jorgensen H, Nakayama H, Raaschou HO, Olsen TS. Stroke in patients with diabetes: The Copenhagen Stroke Study. Stroke 1994; 25(10):1977-84.

10. UK Prospective Diabetes Study (UKPDS) Group Intensive blood-glucose control with sulphonylureas or insulin compared with conventional treatment and risk of complications in patients with type 2 diabetes (UKPDS 33). Lancet 1998; 352(9131):837-53.

11. The Diabetes Control and Complications Trial (DCCT) Research Group. Effect of intensive diabetes management on macrovascular events and risk factors in the Diabetes Control and Complications Trial. Am J Cardiol 1995; 75(14):894-903.

12. Nathan DM, Lachin J, Cleary P et al. Intensive diabetes therapy and carotid intima-media thickness in type 1 diabetes mellitus. NEJM 2003; 348(23):2294-303.

13. Sone $\mathrm{H}$, Mizuno S, Ohashi $\mathrm{Y}$ et al. Prevention and therapeutic strategy of metabolic syndrome-implications from the interim results of Japan Diabetes Complications Study (JDCS). Nippon Rinsho 2004; 62(6):1150-7.

14. The Diabetes Control and Complications Trial (DCCT) Research Group. The Effect of Intensive Treatment of Diabetes on the Development and Progression of Long-Term Complications in Insulin-Dependent Diabetes Mellitus. NEJM 1993; 329(14): 977-986.

15. Turner RC, Cull CA, Frighi V et al. Glycemic control with diet, sulfonylurea, metformin, or insulin in patients with type 2 diabetes mellitus: progressive requirement for multiple therapies (UKPDS 49). JAMA 1999; 281(21): 2005-12. 